\title{
SALVAGE OF LIMBS WITH VASCULAR TRAUMA
}

\author{
ANIL DHAL, MATHEW VARGHESE
}

From Maulana Azad Medical College, New Delhi

\begin{abstract}
In an eight-year period we treated 51 cases of vascular injury associated with fractures and/or dislocations or soft-tissue injuries of the limbs. We relied on a clinical diagnosis and immediate exploration of blood vessels rather than the time-consuming procedure of arteriography. All patients were operated on by the orthopaedic residents on duty and not by vascular surgeons. Only $17(33 \%)$ were repaired within six hours of injury. Limb viability with good function was obtained in 38. Complications included six deaths, four amputations, two renal failures and delayed occlusion in one case.
\end{abstract}

Vascular injuries are traditionally managed by vascular surgeons. However, when patients are admitted as orthopaedic emergencies, with major vascular damage complicating their musculoskeletal injuries, precious time may be lost in obtaining the services of a vascular surgeon. Orthopaedic senior residents trained in the management of vascular injuries can save time and limbs. This is very relevant in low-income countries like India where, for various reasons, many patients reach hospital only after a long delay.

\section{MATERIALS AND METHODS}

Patients with suspected vascular injury admitted to the orthopaedic emergency department, underwent exploration on clinical suspicion alone. Pre-operative arteriography was not used except in three cases, for whom it had been performed before they were referred from other centres.

Surgical management included exploration, appropriate stabilisation of bones and joints, reconstruction of injured vessels and management of associated injuries. Most vessels were repaired by end-to-end suture (Fig. 1). When this was not possible, a vein graft was used (Fig. 2). Lateral suture was used in two patients with false aneurysms and adventitial stripping was performed in two with true arterial spasm. Most patients were operated on under regional anaesthesia, continuous epidural or brachial block. Sympathetic blockade was continued for

A. Dhal, MS, Associate Professor

Department of Orthopaedics, Maulana Azad Medical College, New Delhi-110002, India.

M. Varghese, MS, Consultant Orthopaedic Surgeon St Stephen's Hospital, Tis Hazari, New Delhi-110054, India.

Correspondence should be sent to Dr A. Dhal.

(C) 1992 British Editorial Society of Bone and Joint Surgery $0301-620 \mathrm{X} / 92 / 2327 \$ 2.00$

J Bone Joint Surg [ Br] 1992; 74-B :189-94.
48 hours postoperatively. We used an epidural cannula for lower-limb blockade; for the upper limb an intravenous cannula was left in place at the site of the brachial block and five-hourly injections of $0.5 \%$ bupivacaine were given. None of the patients was heparinised. Postoperatively, the limb was nursed at body level. Vasodilatators and dextran (Lomodex; Rallis India Ltd, West Bengal) were used in all cases.

Peroperative and postoperative arteriography was performed to assess the patency of the repaired artery.

The patients were followed up regularly and surgical procedures for nerve injuries and nonunion of fractures were undertaken as necessary.

\section{RESULTS}

We treated 51 patients with vascular injury of the limbs in the orthopaedic emergency department in an eightyear period; there were 47 men and four women.

Table I gives the location of the vascular injuries; 32 had been caused by road accidents (Table II). The time interval between injury and vascular repair, the type of repair, and the final outcome in all 51 patients are shown in Table III.

There were associated limb fractures in 29 patients, dislocations with or without fractures in five, and softtissue injuries in the remaining 17. Table IV lists the various methods of stabilisation used.

There were six deaths and four amputations (Table V). Two of the amputations were in cases of popliteal artery injury and the other two in injury to the superficial femoral artery.

Septicaemia caused three deaths. One patient died from pulmonary embolism confirmed at post-mortem. In this patient both the popliteal artery and the vein had been repaired. One patient died from an associated head injury and another from hypostatic pneumonia (case 51). Acute renal failure developed in two patients. They were treated by haemodialysis and their kidney function 


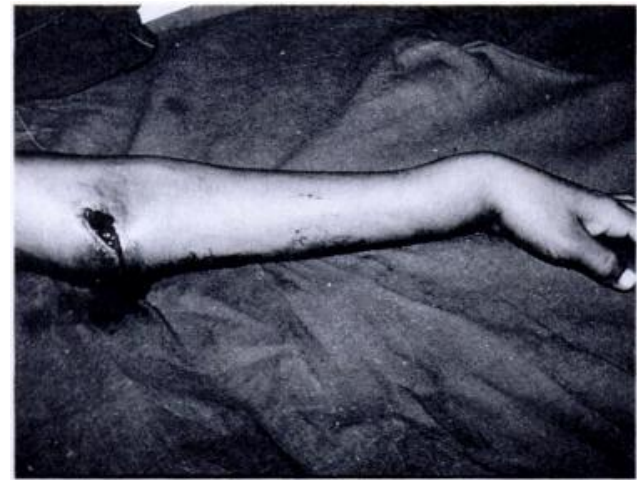

Fig. 1a

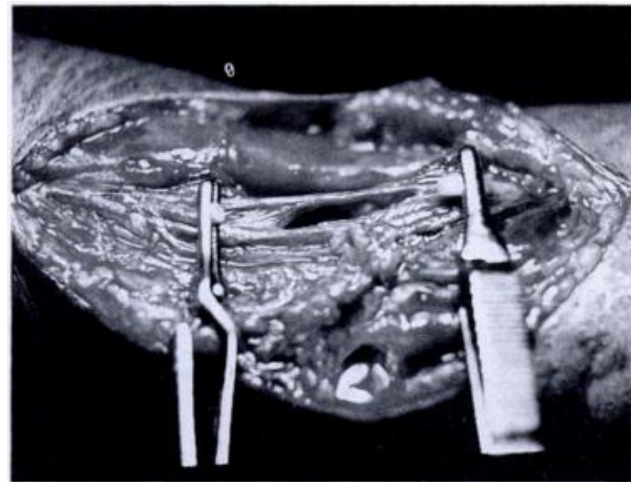

Fig. 1c

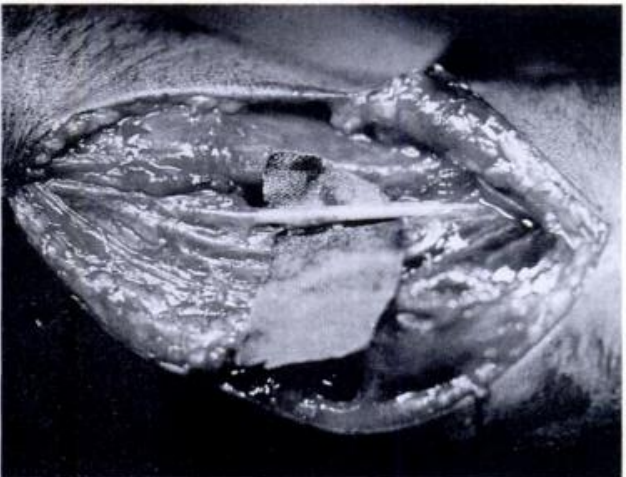

Fig. lb

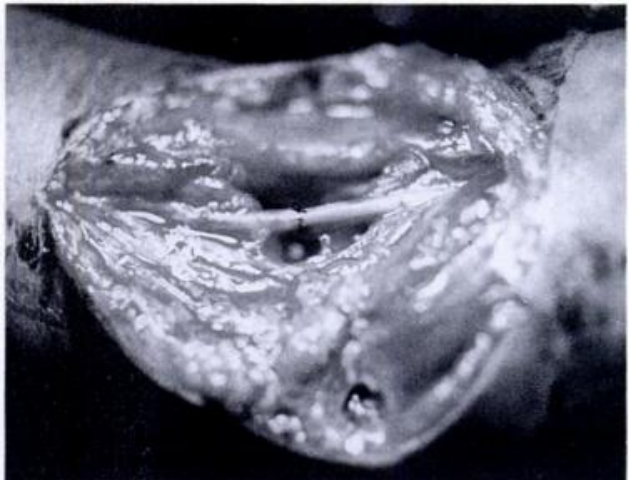

Fig. 1d

Figure 1a - Open supracondylar fracture with an absent radial pulse in a ten-year-old child. Figure $1 \mathrm{~b}-$ Brachial artery contusion found on exploration with no pulsation distal to the lesion. Figure lc - Contused segment excised and bulldog clamps in position. Figure ld - End-to-end anastomosis of brachial artery with the elbow in flexion.

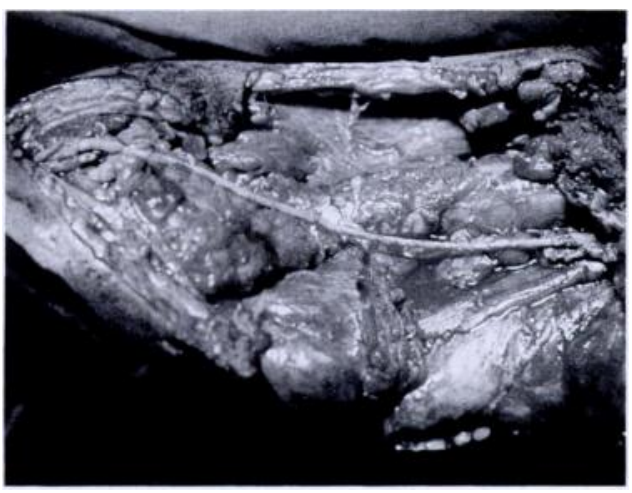

Fig. 2a

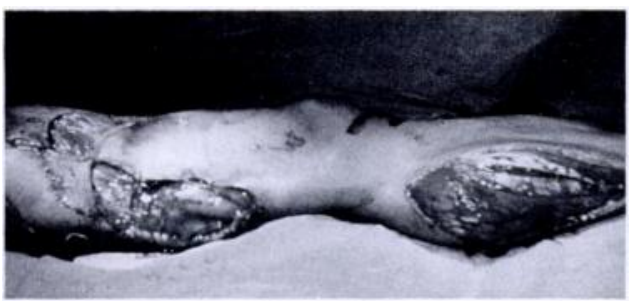

Fig. $2 b$
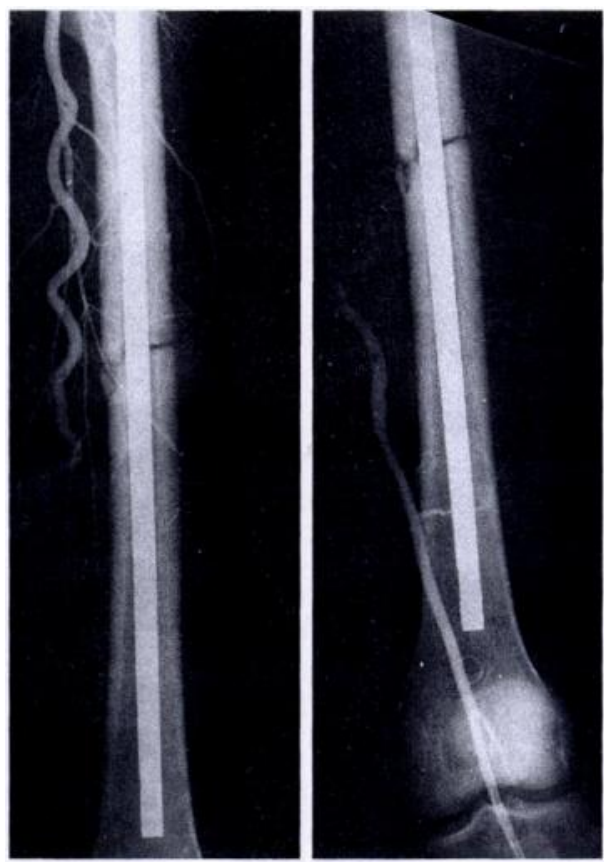

Fig. 2c

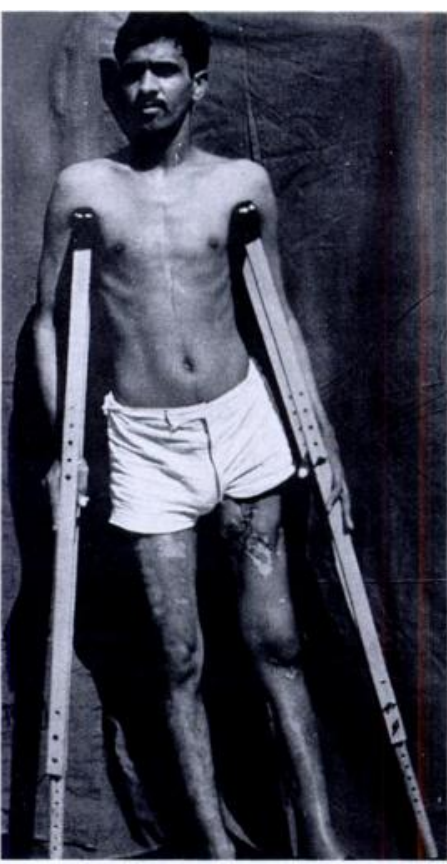

Fig. 2d

Figure $2 \mathrm{a}-\mathrm{A} 20-\mathrm{cm}$-long defect of the femoral artery in the thigh of a 35 -year-old man, bridged by a reversed saphenous vein graft. Figure $2 \mathrm{~b}-$ Immediate postoperative photograph showing distal fasciotomy. The wound was closed after covering the vein graft with a vastus lateralis musclepedicle flap. Figure $2 c$ - Postoperative arteriogram at three months. Fracture stabilised by a Küntscher intramedullary nail. Figure $2 d-C l i n i c a l$ photograph after wound healing. 
subsequently returned to normal. In one patient, in whom the popliteal artery had been anastomosed with the posterior tibial artery, the entire anterior compartment underwent necrosis. This patient, however, is ambulant with a below-knee caliper and has good sensation in the sole of his foot.

\section{DISCUSSION}

Experiences gained in World War II and the Korean and Vietnam wars have greatly influenced present-day vascular surgery. Some earlier reports of vascular injuries (DeBakey and Simeone 1946; Rich, Baugh and Hughes 1969) have dealt only with the injuries of war but with the increasing volume of road traffic there are now reports of civilian vascular trauma (Morris et al 1960; Drapanas et al 1970; Pasch et al 1986). Penetrating injuries are the usual cause of vascular injuries during combat and, even in civilian life, as many as $82 \%$ of such injuries have been caused by gunshot or stab wounds (Feliciano et al 1988). Recently, however, Chervu and Quinones-Baldrich (1988) found the aetiology of civilian vascular injuries to be more varied. Many result from motor-vehicle accidents and accidental falls. Bishara et al (1986) noted that $43 \%$ of such injuries were secondary to blunt trauma and that road accidents were the most common cause. The level of firearm ownership in India is low and in our series there was not a single case of firearm injury.

In our series $34(66 \%)$ of the injuries were associated with fractures and/or joint dislocations. Orthopaedic residents handling road-traffic accidents should therefore be specially trained to look for vascular injuries. In warfare the average interval between injury and surgery decreased from 12 hours in World War II to less than one hour in Vietnam, but in civilian practice in India we find that this time interval continues to be high, at an average of 14.5 hours.

In our country the services of a vascular surgeon are available only in referral centres; procuring such services may therefore add further to the delay and to the risk of losing the limb. We achieved good limb function in $72 \%$ of cases without the help of specialised vascular surgeons; this may be important for other developing countries, where limbs may be amputated in the absence of a vascular specialist. Goodman (1978) also found, in his Vietnam war series, that young surgeons from several different backgrounds could achieve good results by applying the general principles of vascular surgery.

Eger et al (1972) reported that the shortest interval between injury and repair was five hours and the longest 30 hours. Bishara et al (1986) gave an average time interval of 13 hours. It is widely agreed that the operative outcome is related to the time between injury and the establishment of the circulation (Eger et al 1972; Goodman 1978). In view of this we attempted to make a clinical diagnosis and proceed with exploration. Despite our efforts a considerable delay occurred in diagnosing
Table I. Location of the vascular injury in 51 limbs

\begin{tabular}{lclc}
\hline Lower limb & Number & Upper limb & Number \\
\hline Popliteal artery & 18 & Brachial artery & 15 \\
$\begin{array}{l}\text { Superficial femoral artery } \\
\begin{array}{l}\text { Bifurcation of popliteal } \\
\text { arteries }\end{array}\end{array}$ & 7 & Axillary artery & 3 \\
\hline
\end{tabular}

Table II. Cause of injury

\begin{tabular}{|c|c|}
\hline Cause & $\begin{array}{l}\text { Number } \\
\text { injured }\end{array}$ \\
\hline Road-traffic accident & 32 \\
\hline Broken glass & 4 \\
\hline Knife & 2 \\
\hline Industrial accident & 3 \\
\hline Accidental fall & 3 \\
\hline Iatrogenic & $2^{*}$ \\
\hline Others & 5 \\
\hline
\end{tabular}

two patients with false aneurysm of the superficial femoral artery in which distal pulses were palpable. One was diagnosed when there was profuse bleeding from the wound three days after the injury and the other when the distal pulses disappeared about three weeks after admission.

Eger et al (1972) reported that the immediate introduction of temporary arterial shunts enabled them successfully to overcome long delays. We did not use shunts in any of our patients.

Gorman (1968) found that a delay of up to 12 hours was compatible with limb survival, but if this was more than 12 hours the limb could not be saved. Our experience with civilian injuries has not entirely corroborated his findings in combat injuries of the popliteal arteries, probably because of the different extent of damage to the collateral circulation.

There have been many reports of the role of arteriography in vascular trauma (Doty et al 1967; Smith, Szilagyi and Elliott 1969; Snyder 1982; Feliciano et al 1988). Feliciano et al (1988) reported an arteriography rate as high as $64 \%$. McCormick and Burch (1979) found an incidence of false-negative results of $20 \%$ when physical examination was compared with findings on exploration. We did not have any false-negative results and found that a thorough clinical examination was sufficient to diagnose vascular injury. Peroperative arteriography may help, however, when vascularity does not improve after repair, or in ipsilateral double lesions. In one patient with delayed occlusion, postoperative 
Table III. Time interval between injury and vascular repair, type of repair and final outcome

\begin{tabular}{|c|c|c|c|c|c|c|}
\hline Case & Age:sex & Artery & Time (hr) & Type of repair & Fasciotomy & Outcome \\
\hline 1 & $5: F$ & Superficial femoral & 5 & End-to-end & No & Died of head injury \\
\hline 2 & $30: M$ & Superficial femoral & 7 & End-to-end & Yes & Good \\
\hline 3 & $30: \mathbf{M}$ & Superficial femoral & 9 & Vein graft & Yes & BK amputation \\
\hline 4 & $14: M$ & Superficial femoral & 14 & Lateral suture & & Drop-foot \\
\hline 5 & $35: M$ & Superficial femoral & 18 & Vein graft & Yes & Good \\
\hline 6 & $25: M$ & Superficial femoral & 20 & End-to-end & Yes & Necrosis of anterior tibial muscles \\
\hline 7 & $14: M$ & Superficial femoral & 72 & Lateral suture & No & Drop-foot \\
\hline 8 & $12: M$ & Femoropopliteal & 4 weeks & Lateral suture & No & Drop-foot \\
\hline 9 & $18: M$ & Popliteal & 5 & Embolectomy & Yes & BK amputation \\
\hline 10 & $60: M$ & Popliteal & 5 & End-to-end & Yes & Good \\
\hline 11 & $45: M$ & Popliteal & 5 & Thrombectomy & No & Good \\
\hline 12 & $28: M$ & Popliteal & 6 & End-to-end & Yes & Good \\
\hline 13 & $55: \mathrm{M}$ & Popliteal & 6 & End-to-end & Yes & Good \\
\hline 14 & $14: M$ & Popliteal & 6 & Thrombectomy & No & Good \\
\hline 15 & $24: M$ & Popliteal & 6 & End-to-end & Yes & Good \\
\hline 16 & $28: M$ & Popliteal & 6 & Vein graft & Yes & Amputation \\
\hline 17 & $30: \mathbf{M}$ & Popliteal & 7 & End-to-end & Yes & Died of septicaemia \\
\hline 18 & $30: \mathbf{M}$ & Bifurcation popliteal & 7 & End-to-end & Yes & Necrosis of anterior compartment \\
\hline 19 & $33: \mathbf{M}$ & Popliteal & 8 & End-to-end & Yes & Died of pulmonary embolism \\
\hline 20 & $26: M$ & Popliteal & 8 & End-to-end & Yes & Good \\
\hline 21 & $23: \mathbf{M}$ & Popliteal & 14 & End-to-end & Yes & Died of septicaemia \\
\hline 22 & $25: M$ & Popliteal & 18 & End-to-end & Yes & Drop-foot \\
\hline 23 & $45: M$ & Popliteal & 20 & End-to-end & Yes & Good \\
\hline 24 & $10: M$ & Popliteal & 24 & End-to-end & No & Rethrombosis, anaesthetic foot \\
\hline 25 & $50: M$ & Popliteal & 24 & End-to-end & Yes & Good \\
\hline 26 & $35: M$ & Popliteal & 4 & Vein graft & Yes & Amputation \\
\hline 27 & $40: M$ & Axillary & 2 & End-to-end & Yes & Good \\
\hline 28 & $35: M$ & Axillary & 7 & End-to-end & Yes & Intrinsic foot contracture \\
\hline 29 & $30: M$ & Axillary & 8 & End-to-end & Yes & Good \\
\hline 30 & $9: \mathrm{M}$ & Brachial & 2 & End-to-end & Yes & $\begin{array}{l}\text { Case of reimplantation; good } \\
\text { function; no intrinsic recovery }\end{array}$ \\
\hline 31 & $13: M$ & Brachial & 3 & Vein graft & Yes & Good \\
\hline 32 & $40: M$ & Brachial & 4 & End-to-end & Yes & Good \\
\hline 33 & 20:M & Brachial & 5 & Adventitial stripping & Yes & Good \\
\hline 34 & 68:M & Brachial & 5 & End-to-end & Yes & Died of pulmonary infection \\
\hline 35 & $25: M$ & Brachial & 5 & Ligation & Yes & Intrinsic foot contracture \\
\hline 36 & $26: M$ & Brachial & 6 & Vein graft & Yes & Associated median nerve lesion \\
\hline 37 & $18: M$ & Brachial & 6 & End-to-end & Yes & Good \\
\hline 38 & $10: M$ & Brachial & 7 & End-to-end & Yes & Good \\
\hline 39 & $26: M$ & Brachial & 8 & Vein graft & Yes & Associated radial nerve lesion \\
\hline 40 & $12: \mathrm{M}$ & Brachial & 8 & End-to-end & Yes & Good \\
\hline 41 & $32: F$ & Brachial & 8 & End-to-end & Yes & Good \\
\hline 42 & $40: F$ & Brachial & 9 & End-to-end & Yes & Good \\
\hline 43 & 29:M & Brachial & 14 & Ligation & Yes & Good \\
\hline 44 & $15: M$ & Brachial & 24 & End-to-end & Yes & Gangrene of tip of index finger \\
\hline 45 & $30: \mathbf{M}$ & Radial and ulnar & 3 & End-to-end & Yes & Good \\
\hline 46 & $23: M$ & Radial & 4 & Ligation & Yes & Good \\
\hline 47 & $24: M$ & Radial & 4 & Ligation & Yes & Good \\
\hline 48 & $22: M$ & Radial & 5 & End-to-end & Yes & Good \\
\hline 49 & $28: M$ & Radial and ulnar & 5 & End-to-end & Yes & Good \\
\hline 50 & $22: M$ & Radial and ulnar & 5 & End-to-end & Yes & Good \\
\hline 51 & 60:M & Radial and ulnar & 6 & End-to-end & Yes & Died of hypostatic pneumonia \\
\hline
\end{tabular}

Table IV. Method used for stabilising the 34 fractures and dislocations

\begin{tabular}{ll}
\hline Fixation device & Number \\
\hline Plate and screws & 5 \\
Intramedullary nail & 2 \\
Kirschner wires or Rush pins & 6 \\
External fixator & 7 \\
Traction & 1 \\
Plaster of Paris & 13 \\
\hline
\end{tabular}

Table V. The time interval between injury and vascular repair related to the final outcome. The numbers include four ligations (two brachial and two radio-ulnar) and two false aneurysms

\begin{tabular}{llll}
\hline $\begin{array}{l}\text { Time interval } \\
\text { (hours) }\end{array}$ & Number & Deaths & Amputations \\
\hline$<6$ & 17 & 3 & 1 \\
6 to 10 & 21 & 2 & 2 \\
11 to 24 & 10 & 1 & - \\
$>24$ & 3 & - & 1 \\
\hline
\end{tabular}


vascular continuity had been demonstrated arteriographically, but the vessel became obliterated later. We did not use the Doppler probe to measure arterial blood flow as our department does not have this instrument.

As regards fasciotomy Shah et al (1985) have given clinical guidelines for compartment pressure and the viability of the muscle at the time of surgery. We followed the criteria of Goodman (1978). Of the 26 lower-limb vascular injuries $19(73 \%)$ required compartment decompression by fibulectomy but fasciotomy was performed in all upper-limb injuries. Infection of fasciotomy
$30 \%$ in popliteal artery injuries. There was no failure in any of the upper-limb vascular repairs.

Recently, Howard and Makin (1990) proposed that external fixation should be the choice for stabilisation of skeletal injury in vascular cases. In our series, there were three deaths and two amputations in seven cases treated by external fixation, but this was used only for severe grade-III open fractures. The fear that internal fixation will compromise the collateral circulation, also expressed by these authors, is valid only if the vascular repair fails.

Abdul Razek, Mnaymneh and Yacoubian (1973)

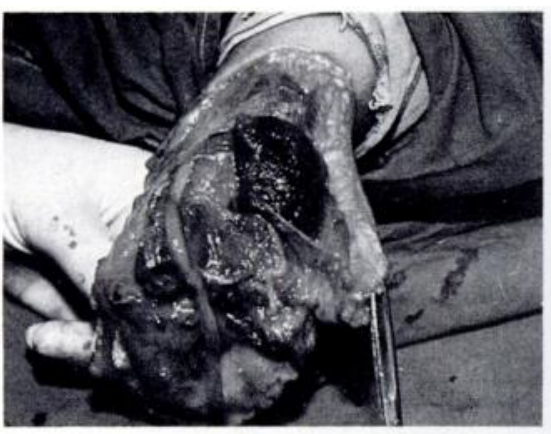

Fig. 3a

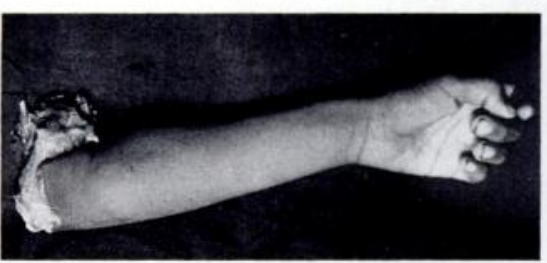

Fig. 3b

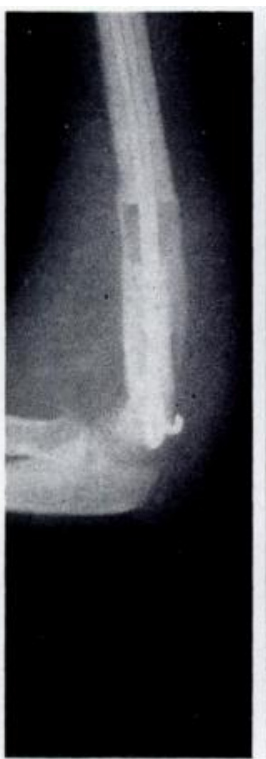

Fig. 3c

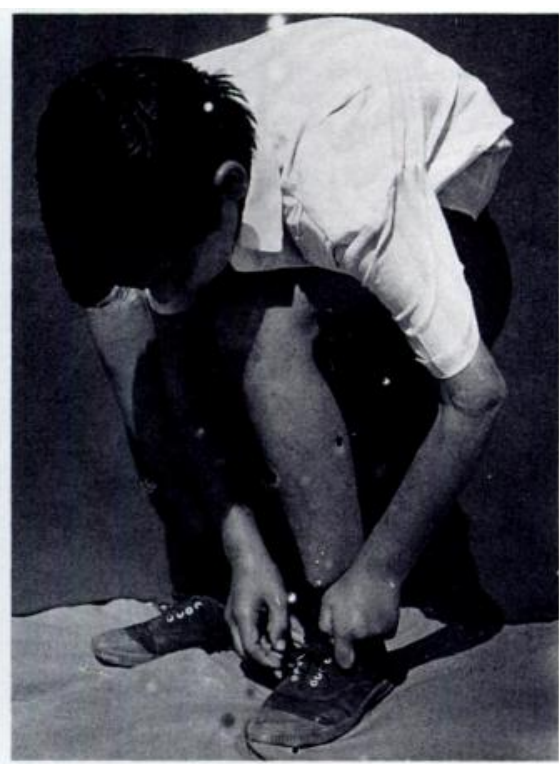

Fig. 3d

Figure 3a-Proximal stump of the left arm of a nine-year-old boy after injury on a fodder cutting machine. Figure $3 b-T h e$ amputated arm. Figure $3 c$ - Six weeks after reimplantation. The fracture was stabilised with Rush pins. Figure $3 d$ - Hand function after reimplantation.

wounds was not a major problem; they all healed well after skin grafting or secondary suturing.

There is always a risk of renal damage in delayed repairs, but we found acute renal failure in only two of our patients; both required haemodialysis. We ensured that there was adequate hydration in all patients after repair and gave diuretics when required as a prophylactic measure. We also gave mannitol and bicarbonate after repair and monitored the urinary output.

Nerve repair, when required, was done as a secondary procedure. Nerve lesions with neurotmesis were seen only in upper-limb injuries. There was no case of nerve injury in lower-limb injuries but in four patients drop-foot persisted after recovery of 'paralysis of ischaemia'. In case 30 in which the arm had been reimplanted all other functions returned to normal except for intrinsic function (Fig. 3).

Failed repair, leading to amputation, occurred only in cases of injury to the popliteal and superficial femoral arteries. Rich et al (1969) also reported a failure rate of reported that unless the limb is obviously beyond salvage, arterial reconstruction should always be attempted, irrespective of the time elapsed since injury. Although we have not hesitated to do primary amputation whenever the limb was severely damaged, we have attempted to save limbs with vascular injury even after considerable delay unless there was obvious gangrene.

No benefits in any form have been received or will be received from a commercial party related directly or indirectly to the subject of this article.

\section{REFERENCES}

Abdul Razek MS, Mnaymneh W, Yacoubian HD. Acute injuries of peripheral arteries with associated bone and soft tissue injuries. $J$ Trauma 1973; 13:907-10.

Bishara RA, Pasch AR, Lim LT, et al. Improved results in the treatment of civilian vascular injuries associated with fractures and dislocations. J Vasc Surg 1986; 3:707-11.

Chervu A, Quinones-Baldrich WJ. Vascular complications in orthopedic surgery. Clin Orthop 1988; 235:275-88.

DeBakey ME, Simeone FA. Battle injuries of the arteries in World War II: an analysis of 2471 cases. Ann Surg 1946; 123:534-79. 
Doty DB, Treiman RL, Rothschild PD, et al. Prevention of gangrene due to fractures. Surg Gynecol Obstet 1967; 125:284-8.

Drapanas T, Hewitt RL, Weichert RF III, Smith AD. Civilian vascular injuries: a critical appraisal of three decades of management. Ann Surg 1970; 172:351-60.

Eger M, Golcman L, Schmidt B, Hirsch M. Problems in the management of popliteal artery injuries. Surg Gynecol Obstet 1972; 134:921-6.

Feliciano DV, Herskowitz K, O'Gorman RB, et al. Management of vascular injuries in the lower extremities. J Trauma 1988; 28: 319-28.

Goodman C. Management of acute arterial injuries. In: Rich NM, Spencer FC, eds. Vascular trauma. Philadelphia, etc: WB Saunders Co, 1978:75-105.

Gorman JF. Combat wounds of the popliteal artery. Ann Surg 1968; $168: 974-80$.

Howard PW, Makin GS. Lower limb fractures with associated vascular injury. J Bone Joint Surg [ Br] 1990; 72-B:116-20.
McCormick TM, Burch BH. Routine angiographic evaluation of neck and extremity injuries. $J$ Trauma 1979; 19:384-7.

Morris GC Jr, Beall AC Jr, Roof WR, DeBakey ME. Surgical experience with 220 acute arterial injuries in civilian practice. Am J Surg $1960 ; 99: 775-81$.

Pasch AR, Bishara RA, Lim LT, et al. Optimal limb salvage in penetrating civilian vascular trauma. $J$ Vasc Surg 1986; 3:189-95.

Rich NM, Baugh JH, Hughes CW. Popliteal artery injuries in Vietnam. Am J Surg 1969; 118:531-4.

Shah DM, Naraynsingh V, Leather RP, Corson JD, Karmody AM. Advances in the management of acute popliteal vascular blunt injuries. J Trauma $1985 ; 25: 793-7$.

Smith RF, Szilagyi DE, Elliott JP. Fracture of long bones with arterial injury due to blunt trauma: principles of management. Arch Surg 1969; 99:315-24.

Snyder WH III. Vascular injuries near the knee: an updated series and overview of the problem. Surgery 1982; $91: 502-6$. 